\title{
PENENTUAN NISBAH BAGI HASIL PADA PEMBIAYAAN MUDHARABAH DAN PERLAKUAN AKUNTANSINYA (Studi Kasus pada KSPPS BMT NU Cabang Wringin Kabupaten Bondowoso) Iin Fadilatul Imamah1
}

1. Jurusan Akuntansi Fakultas Ekonomi Muhammadiyah Jember

\author{
A R T I C L E I N F O \\ Article history: \\ Received 2 January 2019 \\ Received in revised form \\ 09 May 2019 \\ Accepted 06 June 2019 \\ Available online 15 June \\ 2019 \\ Kata Kunci: \\ Bagi Hasil, Pembiayaan \\ Mudharabah, PSAK No.105. \\ Keywords: \\ Profit Sharing, Mudharabah \\ Financing, PSAK No.105.
}

\begin{abstract}
A B S T R A K
Penelitian ini bertujuan untuk mengetahui penentuan nisbah bagi hasil dan untuk menganalisis perlakuan akuntansi pada produk pembiayaan mudharabah. Lembaga keuangan syariah yang dijadikan objek dalam penelitian ini adalah Koperasi Simpan Pinjam dan Pembiayaan Syariah (KSPPS) BMT NU Cabang Wringin Kabupaten Bondowoso. Penelitian ini dilakukan dengan wawancara langsung dengan kepala cabang atau pimpinan BMT NU Cabang Wringin dan mendeskripsikan seluruh data penentuan nisbah bagi hasil pada pembiayaan mudharabah yang kemudian menganalisis kesesuaian akuntansi pembiayaan mudharabah yang ada pada BMT NU dengan PSAK No. 105. Berdasarkan penelitian yang sudah dilakukan, dapat disimpulkan bahwa penentuan nisbah bagi hasil pada produk pembiayaan mudharabah mengunakan metode perhitungan pendapatan kotor rata-rata dan perlakukan akuntansi mengenai pengakuan, pengukuran, penyajian dan pengungkapan pada pembiayaan mudharabah masih ada yang belum sesuai dengan PSAK No. 105.
\end{abstract}

Kata Kunci: Bagi Hasil, Pembiayaan Mudharabah, PSAK No.105.

\section{A B S T R A C T}

This study aims to determine the determination of profit sharing ratio and to analyze the accounting treatment on mudharabah financing products. Shariah financial institutions that are used as objects in this study is a Savings and Loans Cooperative and Sharia (KSPPS) BMT NU Branch Wringin Bondowoso. This research is conducted by direct interview with head of branch or head of BMT NU Wringin Branch and describe all data of determination of profit sharing ratio in mudharabah financing which then analyze the suitability of mudharabah financing accounting in BMT NU with PSAK no. 105. Based on the research that has been done, it can be concluded that the determination of profit sharing ratio in the mudharabah financing product using the method of calculating the average gross income and treating the accounting on the recognition, measurement, presentation and disclosure on mudharabah financing still exist that is not in accordance with the PSAK. 105.

Keywords: Profit Sharing, Mudharabah Financing, PSAK No.105.

Copyright @ Ekuitas: Jurnal Pendidikan Ekonomi. All rights reserved.

\section{Pendahuluan}

Perekonomian syariah di dunia berkembang pesat, salah satunya di Indonesia yang memiliki jumlah penduduk muslim sangat tinggi. Perkembangan ekonomi syariah di Indonesia ini disambut oleh pelaku bisnis dengan mendirikan jasa lembaga keuangan syariah baik itu bank maupun koperasi yang membuat unit khusus berorientasikan syariah dengan menerapkan prinsip-prinsip islam dalam kegiatan transaksi maupun perbankan. Prinsip yang diterapkan dalam ekonomi syariah tanpa adanya bunga melainkan dengan prinsip bagi hasil, antara lain melalui transaksi mudharabah.

Prinsip syariah adalah prinsip hukum Islam dalam kegiatan usaha koperasi berdasarkan fatwa yang dikeluarkan oleh Dewan Syariah Nasional Majelis Ulama Indonesia (DSN-MUI). Dalam prinsip syariah,

*Corresponding author:

Email addresses : iinf5642@gmail.com (Iin Fadilatul Imamah) 
lembaga keuangan menginvetasikan dana yang disimpan pada bank atau koperasi syariah (dana pemilik lembaga keuangan maupun dana rekening investasi) dengan menggunakan alat investasi yang sesuai dengan syariah islam. Investasi yang sesuai dengan syariah Islam tersebut meliputi akad Murabahah, Ijarah, Musyarakah, Mudharabah, Salam, dan Istihna.

Penyaluran dana dengan prinsip bagi hasil (profit sharing) merupakan sebuah karakteristik dari suatu lembaga keuangan syariah dan dasar bagi operasional lembaga keuangan syariah secara keseluruhan (Timami, 2013). Secara syariah prinsip ini didasarkan pada kaidah al-mudharabah, dalam hal ini lembaga keuangan syariah akan bertindak sebagai mitra antara orang yang memiliki kelebihan dana dan orang yang kekurangan dana, dengan penabung lembaga keuangan akan bertindak sebagai pengelola dana (mudharib), sementara penabung akan bertindak sebagai pemilik dana (shahibul maal). Antara keduanya diadakan akad mudharabah, yang menyatakan pembagian keuntungan masing-masing pihak yang terkait. Fungsi dasar lembaga keuangan syariah secara umum tidak jauh berbeda dengan lembaga keuangan konvensional, sehingga prinsip umum dalam pengaturan dan pengawasan lembaga keuangan yang diberlakukan pada lembaga keuangan konvensional juga terdapat pada lembaga keuangan syariah. Namun terdapat perbedaan yang cukup mendasar dalam operasional lembaga keuangan syariah, yaitu:

1. Perlunya jaminan pemenuhan ketaatan pada prinsip syariah dalam seluruh aktivitas lembaga keuangan. 2 .Perbedaan karakteristik operasionalnya khususnya adanya pelarangan bunga dengan prinsip bagi hasil.

Fungsi dari LKS adalah intermediasi antara masyarakat yang kelebihan dana dan masyarakat yang membutuhkan dana (Hafisman, 2013). KSPPS Baitul Maal wat Tamwil Nahdatul Ulama sebagai Lembaga Keuangan Syariah (LKS) mikro memiliki segmentasi menengah ke bawah. Untuk memulai suatu usaha diperlukan modal seberapapun kecilnya, adakalanya orang mendapat modal dari simpanannya atau dari keluarganya bahkan rekan-rekannya. Modal yang yang dirasa masih belum cukup, peran institusi keuangan menjadi sangat penting karena dapat menyediakan modal bagi orang yang ingin berusaha.

Salah satu lembaga keuangan yang bergerak dalam bidang syariah atau dengan prinsip bagi hasil adalah Koperasi Simpan Pinjam dan Pembiayaan Syariah (KSPPS) BMT NU. Berdasarkan Keputusan Menteri Negara Koperasi dan Usaha Kecil dan Menengah Republik Indonesia Nomor 16/Per/M.KUKM/IX/2015 tentang Pentunjuk Pelaksanaan Kegiatan Usaha Koperasi Simpan Pinjam dan Pembiayaan Syariah (KSPPS) yang mana memberikan pengertian bahwa Kopersai Simpan Pinjam dan Pembiayaan Syariah (KSPPS) adalah koperasi yang kegiatan usahanya meliputi simpanan, pinjaman dan pembiayaan sesuai prinsip syariah, termasuk mengelola zakat, sedekah, dan wakaf.

Salah satu produk pembiayaan yang dikembangkan dan ditawarkan oleh Koperasi Simpan pinjam dan Pembiayaan Syariah (KSPPS) BMT NU adalah Pembiayaan Mikro Syariah. Pembiayaan Mikro Syariah ini bertujuan untuk mengembangkan usaha-usaha mikro dengan akad mudharabah dimana KSPP Syariah BMT NU sebagai Shahibul Maal (pemilik dana) dan nasabah sebagai Mudharib (pengelola dana) yang nantinya keuntungan usaha dibagi menurut kesepakatan dalam kontrak. Menurut Antonio (2001) mengatakan dalam pembiayaan mudharabah keuntungan usaha dibagi menurut kesepakatan dalam kontrak, sedangkan apabila rugi ditanggung oleh pemilik modal selama kerugian itu bukan akibat kelalaian pengelola dana (mudharib). Sendainya kerugian itu diakibatkan karena kecurangan atau kelalaian pengelola, pengelola harus bertanggung jawab atas kerugian tersebut.

PSAK No.105 paragraf 11 menjelaskan bahwa pembagian hasil usaha mudharabah dapat dilakukan berdasarkan prinsip revenue sharing atau profit sharing. Berdasarkan prinsip revenue sharing maka dasar pembagian hasil usaha adalah laba bruto (gross profit) bukan total pendapatan usaha (omset) sedangkan jika berdasarkan prinsip profit sharing dasar pembagian adalah laba neto (net profit) yaitu laba bruto dikurangi beban yang berkaitan dengan pengelolaan dana mudharabah. KSPPS BMT NU sebagai LKS yang mempunyai produk dengan akad mudharabah, maka harus menerapkan PSAK No.105 tentang Akuntansi Mudharabah yang merevisi PSAK No. 59 tentang Akuntansi Perbankan Syariah Pelaksanaan prinsip bagi hasil dalam hal penghimpunan dana pada lembaga keuangan syariah cukup mendapat kepercayaan oleh masyarakat, akan tetapi berbeda dengan penyaluran dana yang dilakukan oleh lembaga keuangan syariah masih cukup banyak masyarakat yang beranggapan bahwa prinsip bagi hasil tidak berbeda halnya dengan prinsip bunga yang diterapkan oleh bank konvensional yang membuat banyak orang masih enggan untuk mengembangkan usahanya melalui lembaga keuangan syariah.

Penentuan nisbah bagi hasil yang dilakukan oleh Lembaga Keuangan Syariah masih banyak yang mengedepankan keuntugan semata tanpa melihat kerugian yang dialami oleh nasabah . Lembaga Keuangan Syariah sebaiknya mengedepankan prinsip profit and loss sharing (sistem bagi hasil dan resiko) jika ingin mengedepankan prinsip keadilan dan kebersamaan dalam berusaha, baik dalam memperoleh keuntungan maupun dalam menghadapi resiko. Prinsip dasar pembagian prinsip profit and loss sharing adalah laba neto yaitu laba bruto yang sudah dikurangi beban-beban yang berkaitan dengan pembiayaan mudharabah. Adapun alasan peneliti melakukan penelitian pada KSPPS BMT NU Cabang Wringin Kabupaten Bondowoso karena menurut data yang peneliti peroleh dan hasil wawancara dengan Bapak Jhon selaku kepala cabang 
menyatakan bahwa dalam penentuan nisbah bagi hasil pada KSPPS BMT NU menggunanakan metode perhitungan dengan pendapatan kotor rata-rata, ditinjau dari PSAK No. 105 dalam penentuan nisbah bagi hasil koperasi ini masih belum sesuai. Dalam perlakuan akuntansinya, pembiayaan mudharabah beberapa ketentuan yang telah ditetapkan tersebut tidak dilaksanakan dengan maksimal sehingga kurang adanya kesesuaian antara PSAK No. 105 dengan praktek yang dilakukan oleh KSPPS BMT NU Cabang Wringin Kabupaten Bondowoso. Berdasarkan latar belakang yang telah dipaparkan, peneliti tertarik untuk melakukan penelitian tentang penentuan nisbah bagi hasil pada pembiayaan mudharabah dan menganalisis perlakuan akuntansinya pada lembaga keuangan syariah KSPPS BMT NU Cabang Wringin Kabupaten Bondowoso.

\section{Metode}

Penelitian ini merupakan penelitian kualitatif dengan analisis deskriptif, yaitu metode yang dilakukan dengan cara mengumpulkan, mempersiapkan, serta menganalisis data sehingga mendapat gambaran yang jelas mengenai masalah yang diteliti. Metode analisis deskriptif bertujuan untuk mendeskripsikan secara sistematis, faktual, dan akurat mengenai fakta-fakta, sifat-sifat serta hubungan antar fenomena yang diteliti (Nawawi, 1998). Metode penelitian kualitatif ini sering disebut meode penelitian naturalistik karena penelitiannya dilakukan pada kondisi yang alamiah (natural setting), disebut juga sebagai metode kualitatif karena data yang terkumpul dan anlisisnya lebih bersifat kualitatif. (sugiyono, 2015).

Menjelaskan tempat, organisasi, satuan, atau lembaga yang dijadikan sasaran penelitian, disertai dengan pertimbangan alasan memilih lokasi tersebut. Pertimbangan yang dikemukakan selayaknya pertimbangan-pertimbangan ilmiah yang dikaitkan dengan permasalah penelitian (Sanusi, 2011). Penelitian ini menggunakan Koperasi simpan pinjam dan pembiayaan syariah (KSPPS) BMT NU Cabang Wringin yang berada di jalan Raya wringin Kabupaten Bondowoso.

Adapun Jenis data yang dilakukan penelitian ini adalah:

1. Data Primer

Data primer merupakan data yang pertama kali dicatat dan dikumpulkan oleh peneliti. Data primer dalam penenlitian ini didapatkan dari proses wawancara terhadap informan terkait yaitu Kepala Cabang, juru maal dan umum sebagai informan pendukung pada KSPPS BMT NU Cabang Wringin.

2. Data Sekunder

Data penelitian yang diperoleh peneliti secara tidak langsung melalui media perantara atau diperoleh dan dicatat dari pihak lain maupun dokumen-dokumen. Pada penelitian ini, data sekunder diperoleh dari buku profil, laporan keuangan tahunan, dan dokumen yang terkait yang sesuai dengan tujuan penulisan. Data sekunder ini dianalisis bersama dengan data primer.

Metode pengumpulan data yang digunakan dalam penelitian ini adalah sebagai berikut:

1. Wawancara

Wawancara adalah proses untuk memperoleh data untuk penelitian dengan cara tanya jawab, sambil bertatap muka antara penanya dan narasumber. Teknik wawancara pada penelitian ini adalah teknik wawancara terstruktur kepada pihak-pihak yang terkait, yaitu karyawan dan mudharib yang berkaitan dengan pembiayaan mudharabah pada KSPPS BMT NU.

2. Dokumentasi

Metode dokumentasi adalah metode pencairan dan pengumpulan data mengenai, catatan, bukubuku, majalah dan sebagainya. Adapun data yang terkait dengan pembiayaan mudharabah yang ada di KSPPS BMT NU dan data atau laporan yang ada di mudharib.

Analisis data dalam penelitian ini dilakukan pada saat pengumpulan data berlangsung, dan setelah selesai pengumpulan data dalam periode tertentu. Oleh karena itu, analisis data disini berfungsi untuk memberi arti, makna dan nilai yang terkandung dalam data tersebut. Teknik yang digunakan dalam penelitian ini adalah deskriptif kualitatif, yaiu suatu penelitian yang dimaksud untuk mendeskripsikan suatu situasi tertentu yang bersifat faktual secara sistematis dan akurat.

Tahapan-tahapan dalam penelitian ini adalah:

1. Menganalisis penentuan nisbah bagi hasil pada pembiayaan mudharabah di BMT NU melalui wawancara.

2. Menganalisis konsep pengakuan, pengukuran, penyajian dan pengungkapan pembiayaan mudharabah pada BMT NU.

3. Pemahaman terhadap konsep pengakuan, pengukuran, penyajian dan pengungkapan pembiayaan mudharabah berdasarkan PSAK No. 105 yang dilakukan sebagai studi pustaka.

4. Data-data yang diperoleh dikelompokkan sesuai dengan perlakuan akuntansi mengenai pengakuan, pengukuran, penyajian dan pengungkapan pembiayaan mudharabah. 
5. Menganalisis kesesuaian akuntansi pembiayaan mudharabah yang ada pada BMT NU dengan PSAK No.105.

6. Kesimpulan dan saran

\section{Hasil dan pembahasan}

Prosedur Pembiayaan Mudharabah

Tahapan dalam pembiayaan mudharabah yang harus dilalui sebelum dana mudharabah diserahkan kepada nasabah adalah sebagai berikut :

1. Nasabah Melakukan Pengajuan Pembiayaan Mudharabah

2. Survey Pengajuan Pembiayaan yaitu proses survey dengan mendatangi lokasi usaha anggota yang akan melakukan pembiayaan.

3. Analisis Hasil Survey Pembiayaan, proses analisis dari hasil survey pengajuan pembiayaan ini meliputi data yang diperoleh dari proses pra survey dan proses survey yang telah dilakukan.

4. Komite Pengajuan Pembiayaan, laporan hasil survey yang telah dianalisis dilakukan komite atau pengambilan keputusan apakah pengajuan pembiayaan akan disetujui atau ditolak.

5. Informasi Keputusan Realisasi Pengajuan Pembiayaan, KSPPS BMT NU Cabang wringin Kabupaten Bondowoso akan menginformasikan kepada anggota pemohon mengenai keputusan pembiayaan apakah disetujui atau ditolak.

6. Proses Input Data dan Pencetakan Akad Perjanjian, proses memasukkan data dan pencetakan akad perjanjian dilakukan oleh bagian pembiayaan. Data pengajuan pembiayaan akan dimasukkan sebagai dokumen yang harus tercatat di KSPPS BMT NU Cabang Wringin Kabupaten Bondowoso.

7. Proses Akad dan Pencairan Pembiayaan, dilakukan setelah terealisasikan dan ditandatangani oleh kepala cabang, selanjutnya anggota pemohon pembiayaan datang ke kantor KSPPS BMT NU untuk melakukan akad.

8. Pengarsipan akad Perjanjian dan Dokumen Pembiayaan, pengarsipan dokumen-dokumen pembiayaan meliputi dokumen identitas pengajuan pembiayaan, laporan hasil survey, SP3 dan akad perjanjian.

9. Pemeliharaan Usaha dan Pengembalian Dana Pembiayaan, dilakukan oleh KSPPS BMT NU untuk terus menjalin hubungan baik dengan setiap anggota dalam menangani fasilitas produk pembiayaan agar tetap terjaga silaturrahmi dengan baikdan menjaga loyalitas anggota tersebut.

\section{Penentuan Nisbah Bagi Hasil pada Pembiayaan Mudharabah}

Pembiayaan mudharabah diharapkan memberikan pendapatan investasi pendapatan yang wajar. Untuk memperoleh pendapatan yang wajar BMT NU menentukan expected return 13,50\% (pengembalian investasi yang diharapkan) untuk setiap pembiayaan di KSPPS BMT NU CABANG Wringin Kabupaten Bondowoso.

Prime Rate Komersial dan Kecil

FFR A + Skor Netral

$: 11,00 \%$

$: 1,50 \%$

(Financing Risk Rating)

Ketentuan PDB (+1)

$: 1,00 \%+$

Price yang diberkan kepada Nasabah

$: 13,50 \%$

Pembiayaan mudharabah di KSPPS BMT NU Cabang Wringin Kabupaten Bondowoso, pembagian hasil usaha berdasarkan pendapatan kotor rata-rata. Jumlah tersebut merupakan indikasi hasil yang selanjutnya disepakati sebagai acuan perhitungan pembagian hasil usaha. Untuk lebih memahami sistem penentuan nisbah bagi hasil di KSPPS BMT NU, peneliti memperlihatkan ilustrasi transaksi pembiayaan mudharabah.

\section{Ilustrasi Transaksi Pembiayaan Mudharabah di KSPPS BMT NU Cabang Wringin Kabupaten Bondowoso}

Tanggal 1 April 2017 KSPPS BMT NU menyetujui pemberian fasilitas mudharabah kepada Bapak Ahmad sebesar Rp 30.000.000,- dengan expected return yang berlaku di BMT NU 13,5\% 
dalam jangka waktu 12 bulan untuk membantu pengembangan usaha mebel yang sedang dijalankan.

Perhitungan Nisbah Bagi Hasil pada KSPPS BMT NU

$$
\begin{array}{ll}
\text { Cicilan per bulan } & =\operatorname{Rp~30.000.000/12bulan} \\
& =\operatorname{Rp~2.500.000,-} \\
& =\text { Limit Plafond } \times \text { Expected Return } \\
& =\operatorname{Rp} 30.000 .000 \times 13,5 \% \\
& =\operatorname{Rp} 4.050 .000
\end{array}
$$

Proyeksi Pendapatan 1 Tahun = Rp 4.050.000 × 12

Nisbah BMT NU

$=\operatorname{Rp} 48.600 .000$,-

$$
\begin{aligned}
\text { Nisbah BMT NU } & =(\text { Cicilan perbulan }) /(\text { Proyeksi Pendapatan } 1 \text { tahun }) \times 100 \% \\
& =(\operatorname{Rp} 2.500 .000) /(\operatorname{Rp} 48.600 .000) \times 100 \% \\
& =5,14 \% \\
& =100 \%-5,14 \%=94,86 \%
\end{aligned}
$$

Setelah penentuan nisbah bagi hasil terhadap Bapak Ahmad maka selanjutnya BMT NU melakukan kesepatan dan memberikan Surat Penegasan Persetujuan Pembiayaan (SP3) kepada Bapak Ahmad dengan struktur pembiayaan berikut:

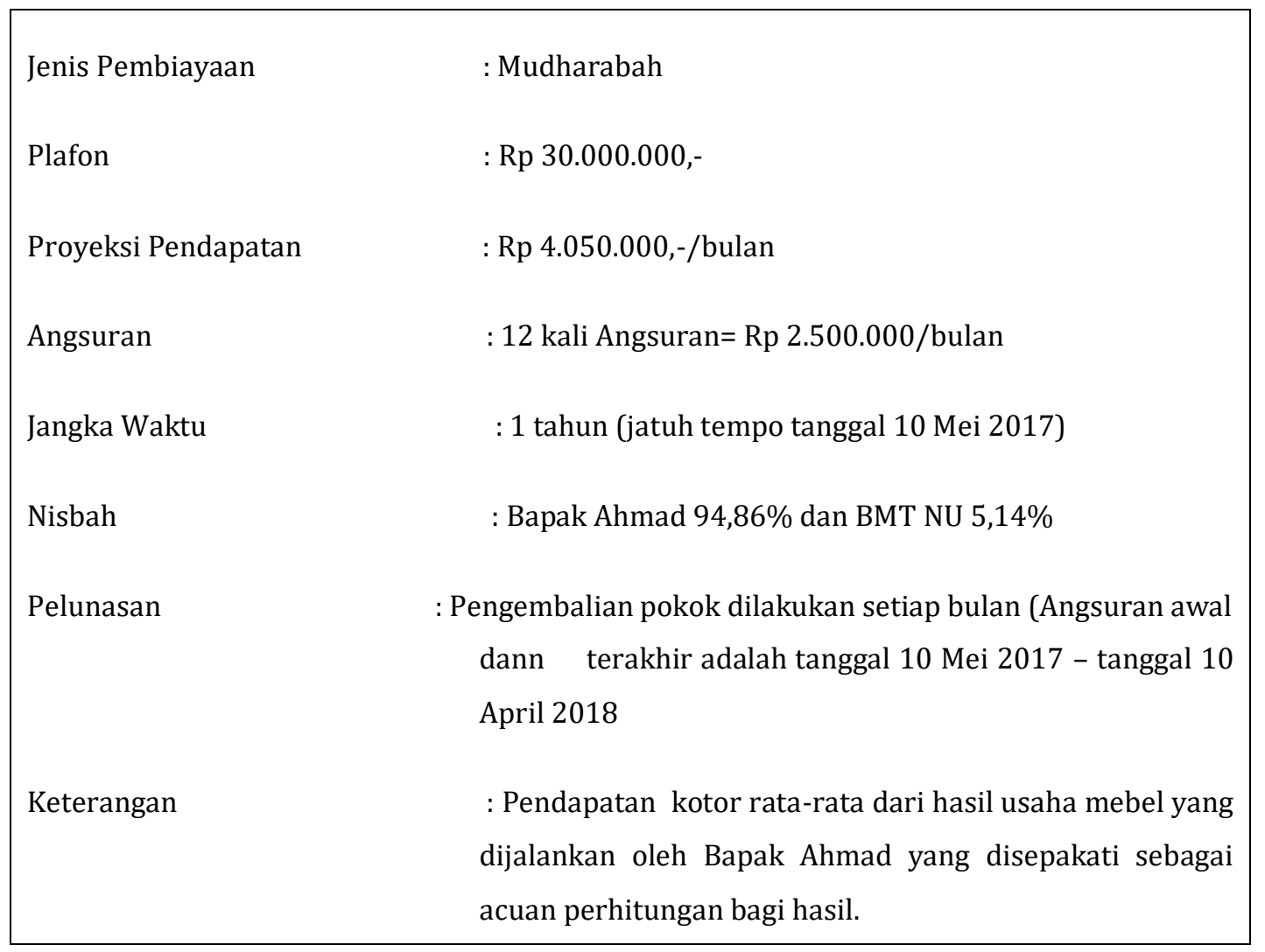

Sumber: KSPPS BMT NU

Pada saat tejadinya transaksi antara BMT NU dengan Bapak Ahmad atau penyerahan modal dari KSPPS BMT NU kepada Bapak Ahmad pada tanggal 10 April 2017, pihak dari BMT NU ini baru akan mengakui pembiayaan mudharabah sebesar Rp 30.000.000,- sebagai investasi mudhrabah dengan jurnal berikut : 


\begin{tabular}{|l|l|l|l|}
\hline Tanggal & Keterangan & Debit & Kredit \\
\hline \multirow{2}{*}{$10 / 04 / 17$} & Investasi Mudharabah & Rp 30.000.000 & \\
\cline { 2 - 4 } & Kas & & Rp 30.000.000 \\
\hline
\end{tabular}

Perhitungan bagi hasil

Nisbah BMT NU

: 5,14\% x Rp 4.050.000,-

: Rp 208.170

Nisbah Bapak Ahmad $\quad$ : 94,86\% x Rp 4.050.000,-

: Rp 3.841 .830

Angsuran Pokok Per Bulan : Rp 2.708.170

Bagi hasil mudharabah untuk porsi BMT NU sebesar Rp 208.170,- berdasarkan metode perhitungan dengan pendapatan kotor rata-rata yang digunakan sebagai acuan perhitungan pembagian hasil usaha yang didapat Bapak Ahmad setiap bulannya. BMT NU akan menjurnal sebagai berikut :

\begin{tabular}{|c|c|c|c|}
\hline Tanggal & Keterangan & Debit & Kredit \\
\hline \multirow[t]{2}{*}{$10 / 05 / 17$} & Kas & Rp 208.170 & \\
\hline & Pendapatan Bagi Hasil & & Rp 208.170 \\
\hline
\end{tabular}

Jika Mudharib Mengalami Kerugian dalam Menjalankan Usahanya

Usaha mebel yang dijalankan oleh Bapak Ahmad mengalami kerugian sebesar Rp 1.000.000,- akibat pemadaman listrik yang sering terjadi. penyebab penurunan tersebut bukan karena kelalaian dan kesalahan Bapak Ahmad maka dalam hal ini BMT NU akan menanggung kerugian tersebut dengan memperhitungkan pada saat bagi hasil. Karena kehilangan Rp 1.000.000,- jadi Proyeksi Pendapatan $=\mathrm{Rp}$ 4.050 .000 - Rp 1.000.000,- = Rp 3.050.000.

Perhitungan Nisbah bagi hasil sebagai berikut:

Bagi hasil untuk Bapak Ahmad $\quad$ : 94,86\% x Rp 3.050.000,-

Bagi hasil untuk BMT NU

: Rp 2.893.230,-

: 5,14\% x Rp 3.050.000,-

: Rp 156.770

maka dalam hal ini KSPPS BMT NU akan menjurnal atas transaksi tersebut pada saat bagi hasil sebagai berikut :

\begin{tabular}{|l|l|l|l|}
\hline Tanggal & Keterangan & Debit & Kredit \\
\hline 10/09/17 & Piutang Bagi Hasil Investasi Mudharabah & Rp 156.770 & \\
& Kerugian Nilai Investasi Mudharabah & Rp 51.400 & \\
\hline & Pendapatan Bagi Hasil Mudharabah & & Rp 208.170 \\
\hline
\end{tabular}

Menurut peneliti pada kasus di atas ketika mudharib mengalami kerugian yang bukan karena kelalaian pengelola dana (mudharib) atau kehilangan modal perlakuan akuntansinya sudah sesuai dengan PSAK No. 105 Paragraf 15 "Jika sebagian investasi mudharabah hilang setelah dimulainya usaha tanpa adanya kelalaian atau kesalahan pengelola dana, maka kerugian tersebut diperhitungkan pada saat bagi hasil".

2. Apabila Mudharib Terlambat Melakukan Pembayaran dari Tanggal Jatuh Tempo yang telah ditentukan

Pada tanggal 10 November 2017 adalah tanggal jatuh tempo pembayaran bagi hasil yang harus dibayarkan Bapak Ahmad kepada BMT NU, tetapi Bapak Ahmad belum membayarkannya maka BMT NU akan mengakui adanya piutang bagi hasi dengan jurnal sebagai berikut : 


\begin{tabular}{|c|c|c|c|}
\hline Tanggal & Keterangan & Debit & Kredit \\
\hline \multirow{2}{*}{$10 / 11 / 17$} & Piutang pendapatan bagi hasil mudhrabah & Rp 208.170 & \\
\cline { 2 - 4 } & Pendapatan bagi hasil mudharabah & & Rp 208.170 \\
\hline
\end{tabular}

Pada tanggal 5 Desember 2017 Bapak Ahmad baru membayarkan porsi bagi hasil untuk BMT NU, karena Bapak Ahmad melakukan pembayaran melebihi jatuh tempo maka Bapak Ahmad dikenakan denda Rp 1000/hari dan keterlambatannya 10 November 5 Desember $=25$ hari jadi Bapak Ahmad dikenakan denda Rp 1000 x 25 hari = Rp 25.000. jurnalnya adalah sebagai berikut:

\begin{tabular}{|c|l|l|l|}
\hline Tanggal & \multicolumn{1}{|c|}{ Keterangan } & Debit & \multicolumn{1}{c|}{ Kredit } \\
\hline 05/12/17 & Kas & Rp 208.170 & \\
\cline { 2 - 4 } & $\begin{array}{l}\text { Piutang pendapatan bagi hasil } \\
\text { mudharabah }\end{array}$ & & Rp 233.170 \\
\cline { 2 - 4 } & Kas & Rp 208.170 & \\
\cline { 2 - 4 } & Pendapatan bagi hasil mudharabah & & Rp 208.170 \\
\hline
\end{tabular}

Perlakuan akuntansi atas pembagian hasil usaha yang dibayarkan terlambat oleh mudharib seperti yang dijelaskan diatas sudah sesuai PSAK No. 105 tentang Akuntansi Mudharabah paragraf 24 "Bagian hasil usaha yang belum dibayar oleh pengelola dana diakui sebagai piutang".

Tabel 1. Daftar Angsuran Pembiayaan Mudharabah Bapak Ahmad

\begin{tabular}{|c|c|c|c|c|c|}
\hline No & $\begin{array}{c}\text { Pokok } \\
\text { Pinjaman }\end{array}$ & Cicilan Pokok & Bagi Hasil & $\begin{array}{l}\text { Angsuran } \\
\text { Perbulan }\end{array}$ & Saldo Pokok \\
\hline 1 & Rp 30.000.000 & Rp 2.500.000 & $\operatorname{Rp} 208.170$ & Rp 2.708.170 & Rp 27.500.000 \\
\hline 2 & Rp 27.500.000 & Rp 2.500.000 & Rp 208.170 & Rp 2.708.170 & Rp 25.000.000 \\
\hline 3 & Rp 25.000.000 & Rp 2.500.000 & Rp 208.170 & Rp 2.708.170 & Rp 22.500.000 \\
\hline 4 & Rp 22.500.000 & Rp 2.500.000 & Rp 156.770 & Rp 2.656.770 & Rp 20.000.000 \\
\hline 5 & Rp 20.000.000 & Rp 2.500 .000 & Rp 208.170 & Rp 2.708.170 & Rp 17.500.000 \\
\hline 6 & Rp 17.500.000 & Rp 2.500.000 & Rp 208.170 & Rp 2.708.170 & Rp 15.000.000 \\
\hline 7 & Rp 15.000.000 & Rp 2.500.000 & $\operatorname{Rp} 208.170$ & Rp 2.708.170 & Rp 12.500.000 \\
\hline 8 & Rp 12.500 .000 & Rp 2.500.000 & Rp 208.170 & Rp 2.708.170 & Rp 10.000.000 \\
\hline 9 & $\operatorname{Rp} 10.000 .000$ & Rp 2.500.000 & Rp 208.170 & Rp 2.708.170 & Rp 7.500 .000 \\
\hline 10 & Rp 7.500 .000 & Rp 2.500.000 & $\operatorname{Rp} 208.170$ & Rp 2.708.170 & Rp 5.000 .000 \\
\hline 11 & Rp $\quad 5.000 .000$ & Rp 2.500.000 & $\operatorname{Rp} 208.170$ & Rp 2.708.170 & Rp 2.500 .000 \\
\hline 12 & Rp 2.500 .000 & Rp 2.500 .000 & Rp 208.170 & Rp 2.708.170 & 0 \\
\hline \multicolumn{4}{|c|}{ Total Angsuran } & \multicolumn{2}{|c|}{ Rp 32.446 .640} \\
\hline
\end{tabular}

Sumber: KSPPS BMT NU 
Perhitungan Nisbah Bagi Hasil yang Sesuai dengan PSAK No. 105

Tanggal1 April 2017 KSPPS BMT NU menyetujui pemberian fasilitas pembiayaan Mudharabah kepada Bapak Ahmad sebesar Rp 30.000.000,- dengan nisbah BMT 10\% dan Bapak Ahmad 90\% dalam jangka waktu 12 bulan untuk membantu pengembangan usaha mebel yang sedang dijalankan dan pembiayaan mudharabah diserahkan kepada Bapak Ahmad tanggal 5 April 2017. Untuk menentukan bagi hasil BMT Nu meminta laporan Laba Rugi berikut:

\section{Laporan Laba Rugi \\ CV Mebel Berkah (Bapak Ahmad)}

Per 30 April 2017

\begin{tabular}{|c|c|c|}
\hline \multicolumn{3}{|l|}{ Penjualan } \\
\hline Almari (10 Unit x Rp 1.500.000) & 15.000 .000 & \\
\hline Meja Belajar (10 Unit x Rp 1.000.000) & 10.000 .000 & \\
\hline Kursi set (10 Unit x Rp 2.000.000) & 20.000 .000 & \\
\hline Total Penjualan & & 45.000 .000 \\
\hline \multicolumn{3}{|l|}{ Harga Pokok Produksi } \\
\hline Pesediaan awal April 2017 & 2.000 .000 & \\
\hline \multicolumn{3}{|l|}{ Pembelian-pembelian } \\
\hline Kayu (170 balok x Rp 130.000) & 22.100 .000 & \\
\hline Plitur (30 Kaleng x Rp 50.000) & 1.500 .000 & \\
\hline Paku (1.000 Ons x Rp 5.000) & 5.000 .000 & \\
\hline Lem (50 Plastik x Rp 25.000) & 1.250 .000 & \\
\hline Total Pembelian & 29.850 .000 & \\
\hline Barang yang tersedia untuk dijual & 31.850 .000 & \\
\hline Persediaan Akhir 30 April 2017 & $(4.000 .000)$ & \\
\hline HPP & & 27.850 .000 \\
\hline Laba Kotor & & 17.150 .000 \\
\hline \multicolumn{3}{|l|}{ Beban Usaha } \\
\hline Biaya Gaji Karyawan & 7.100 .000 & \\
\hline Biaya Listrik & 400.000 & \\
\hline Biaya Air & 100.000 & \\
\hline Biaya Penyusutan & 6.000 .000 & \\
\hline Total Beban Usaha & & 13.600 .000 \\
\hline Laba Bersih & & 3.550 .000 \\
\hline
\end{tabular}

Dalam PSAK No. 105 paragraf 11 " pembagian hasil usaha mudharabah dapat dilakukan berdasarkan prinsip bagi hasil, maka dasar pembagian hasil usaha adalah laba bruto (gross Profit) bukan total pendapatan (omset). Sedangkan jika berdasarkan prinsip bagi laba, dasar pembagian adalah laba neto (net profit) yaitu laba bruto dikurangi beban yang berkaitan dengan pengelolaan dana mudharabah". Jadi perhitungan berdasarkan profit sharing dengan laba bersih yang diperoleh nasabah setiap bulannya seperti berikut: 


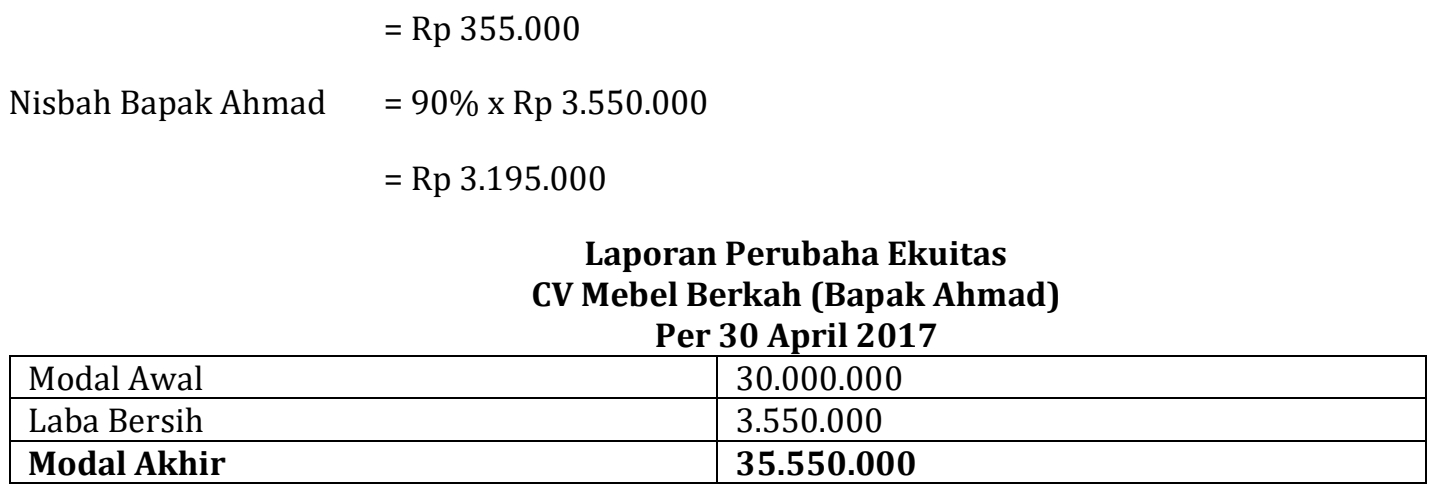

Perlakuan Akuntansi Berdasarkan PSAK No. 105 pada Pembiayaan Mudharabah sebagai Penyedia Dana di KSPPS BMT NU Cabang Wringin Kabupaten Bondowoso

PSAK No. 105 merupakan Pernyataan Standar Akuntansi Keuangan No. 105 yang bertujuan untuk mengatur pengakuan, pengukuran, penyajian dan pengungkapan transaksi mudharabah (pengakuan, pengukuran, penyajian dan pengungkapan), yaitu transaksi khusus yang berkaitan dengan aktivitas koperasi syariah. PSAK ini diterapkan untuk entitas yang melakukan transaksi mudharabah baik sebagai pemilik dana (shahibul maal) maupun pengelola dana (mudharib).

\section{KSPPS BMT NU Cabang Wringin}

Laporan Neraca

Periode 31 Desember 2017

\begin{tabular}{|c|c|c|}
\hline AKTIVA & & PASIVA \\
\hline AKTIVA LANCAR & & KEWAJIBAN JANGKA PENDEK \\
\hline Kas Kantor Cabang & $96.315 .830,80$ & Kewajiban \\
\hline $\begin{array}{l}\text { Rekening BMT NU } \\
\text { Pusat }\end{array}$ & $1.466 .667 .109,85$ & $824.532,02$ \\
\hline Pembiayaan & $1.377 .584 .700,00$ & $\begin{array}{l}\text { Dana Nu dan } \\
\text { Lingkungan }\end{array}$ \\
\hline $\begin{array}{l}\text { Bebean dibayar } \\
\text { dimuka }\end{array}$ & $83.002 .449,22$ & Dana Promosi \\
\hline Sewa dibayar dimuka & $70.250 .000,00$ & $3.833 .536,08$ \\
\hline Perlengkapan & $2.174 .257,93$ & Dana Titipan Ziz \\
\hline \multirow[t]{2}{*}{ Total Aktiva Lancar } & $3.096 .994 .347,80$ & Dana Bina Mitra \\
\hline & & $\begin{array}{l}\text { Total Kewajiban } \\
\text { Jangka Pendek }\end{array}$ \\
\hline AKTIVA TETAP & & $\begin{array}{l}\text { KEWAJIBAN JANGKA } \\
\text { PANJANG }\end{array}$ \\
\hline Peralatan & $193.714 .000,00$ & $\begin{array}{l}\text { Pembiayaan } \\
\text { Mudharabah }\end{array}$ \\
\hline $\begin{array}{l}\text { Ak. Penyustan } \\
\text { Peralatan }\end{array}$ & $(36.137 .405,00)$ & $\begin{array}{l}\text { Pembiayaan } \\
\text { Musyarakah }\end{array}$ \\
\hline Gedung & $218.526 .086,00$ & $\begin{array}{l}\text { Total Kewajiban } \\
\text { Jangka Panjang }\end{array}$ \\
\hline Ak. Peny. Gedung & $(29.063 .970 .61)$ & Modal \\
\hline Kendaraan Roda Dua & $15.318 .000,00$ & Simpanan Anggota \\
\hline $\begin{array}{l}\text { Ak. Penyu. Kend Roda } \\
\text { Dua }\end{array}$ & $(769.900,00)$ & Donasi/Hibah \\
\hline Software IT & $10.000 .000,00$ & SHU Bulan Berjalan \\
\hline $\begin{array}{l}\text { Ak. Amortisasi } \\
\text { Software }\end{array}$ & $(1.520 .000,00)$ & Modal BMT Pusat \\
\hline Total Aktiva Tetap & $370.070 .810,39$ & Bagi Hasil Tabungan \\
\hline Jumlah Aktiva & $3.466 .065 .158,19$ & $3.466 .065 .158,19$ \\
\hline
\end{tabular}

Sumber: Laporan Neraca KSPPS BMT NU 


\section{Pengakuan dan Pengukuran}

Tabel 2. Pengakuan dan Pengukuran Pembiayaan Mudharabah KSPPS BMT NU Cabang Wringin Kabupaten Bondowoso.

\begin{tabular}{|c|c|c|}
\hline PSAK No. 105 & KSPPS BMT NU & Hasil Analisis \\
\hline $\begin{array}{l}\text { Dana Mudharabah yang disalurkan oleh pemilik } \\
\text { dana diakui sebagai investasi mudharabah pada } \\
\text { saat pembayaran kas atau penyerahan aset } \\
\text { nonkas kepada pengelola dana. } \\
\text { (Paragraf } 12 \text { ) }\end{array}$ & $\begin{array}{l}\text { Pencatatan pada saat } \\
\text { penyerahan pembiayaan } \\
\text { mudharabah kepada Bapak } \\
\text { Ahmad } \\
\text { Dr. Investasi Mudharabah } \\
\text { Cr. Kas }\end{array}$ & Sesuai \\
\hline $\begin{array}{l}\text { Jika sebagian Investasi mudharabah hilang } \\
\text { setelah dimulainya usaha tanpa adanya kelalaian } \\
\text { atau kesalahan pengelola dana, maka kerugian } \\
\text { tersebut diperhitungkan pada saat bagi hasil. } \\
\text { (paragraf 15) }\end{array}$ & $\begin{array}{l}\text { Pencatatan saat Bapak Ahmad } \\
\text { mengalami Kerugian dan bukan } \\
\text { karena kelalaiannya } \\
\text { Dr. Piutang Bagi Hasil } \\
\text { Dr. Kerugian nilai investasi } \\
\text { Cr. Pend. Bagi hasil }\end{array}$ & Sesuai \\
\hline $\begin{array}{l}\text { Pengakuan penghasilan usaha mudharabah dalam } \\
\text { praktik dapat diketahui berdasarkan laporan bagi } \\
\text { hasil atas realisasi penghasilan usaha dari } \\
\text { pengelola dana. Tidak diperkenankan mengakui } \\
\text { pendapatan dari proyeksi hasil usaha. } \\
\text { (paragraf 22) }\end{array}$ & 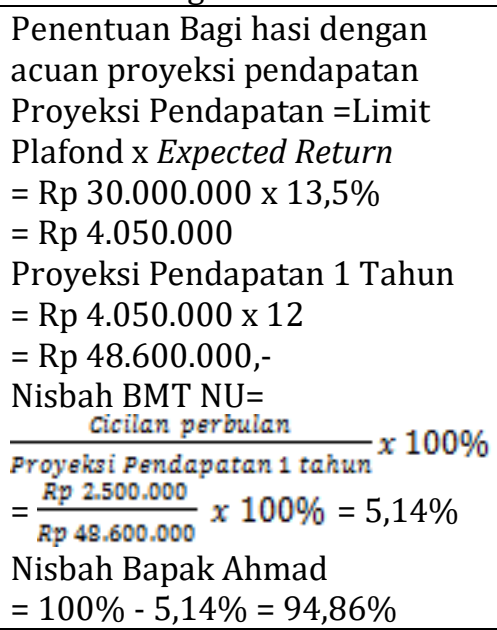 & Tidak Sesuai \\
\hline $\begin{array}{l}\text { Bagian hasil usaha yang belum dibayar oleh } \\
\text { pengelola dana diakui sebagai piutang. } \\
\text { (Paragraf } 24 \text { ) }\end{array}$ & $\begin{array}{l}\text { Pencatatan saaat Bapak Ahmad } \\
\text { Menunggak Pembayaran bagi } \\
\text { hasil } \\
\text { Dr. Piutang Pend. Bagi hasil } \\
\text { Cr. Pend bagi hasil }\end{array}$ & Sesuai \\
\hline
\end{tabular}

Sumber: Data diolah

Tabel 4.6 Penyajian Pembiayaan Mudharabah pada KSPPS BMT NU Cabang Wringin Kabupaten Bondowoso

\begin{tabular}{|l|l|c|}
\hline PSAK No. 105 & KSPPS BMT NU & Tidak Sesuai \\
\hline Pemilik dana menyajikan investasi mudharabah & Pencatatan pada saat & \\
dalam laporan keuangan sebesar nilai tercatat. & penyerahan pembiayaan & \\
(Paragraf 36) & mudharabah Rp30.000.000 & Sesuai \\
& kepada Bapak Ahmad & \\
& Dr.Investasi Mudharabah & \\
& 30.000 .000 & \\
\hline
\end{tabular}

Sumber: Data diolah 
Tabel 4.6 Pengungkapan Pembiayaan Mudharabah pada KSPPS BMT NU Cabang Wringin

\section{Kabupaten Bondowoso}

\begin{tabular}{|c|c|c|}
\hline PSAK No. 105 & Sesuai & Tidak Sesuai \\
\hline $\begin{array}{l}\text { Pemilik dana mengungkapkan hal-hal terkait transaksi mudharabah, } \\
\text { tetapi tidak terbatas pada: } \\
\text { a. Isi kesepakatan utama usaha mudharabah, seperti porsi dana, } \\
\text { pembagian hasil usaha, aktivitas usaha mudharabah dan lain- } \\
\text { lain; } \\
\text { b. Rincian jumlah investasi mudharabah berdasarkan jenisnya; } \\
\text { c. Penyisihan kerugian investasi mudharabah selama periode } \\
\text { berjalan; } \\
\text { (Paragraf 38) }\end{array}$ & $\sqrt{ }$ & $\sqrt{ }$ \\
\hline
\end{tabular}

Sumber: Data diolah

\section{Simpulan dan saran}

Berdasarkan penelitian tentang penentuan nisbah bagi hasil pada pembiayaan mudharabah dan menganalisis perlakuan akuntansinya pada lembaga keuangan syariah di KSPPS BMT NU Cabang Wringin Kabupaten Bondowoso. Kesimpulan yang dapat diperoleh dari pembahasan yang telah dijelaskan sebelumnya adalah :

1. Pembiayaan mudharabah yang dilakukan oleh KSPPS BMT NU Cabang Wringin Kabupaten Bondowoso sangat baik dan prosedur pembiayaannya tertata dengan rapi dan jelas, sehingga untuk nasabah yang akan melakukan pembiayaan mudharabah ini dalam proses pencairan dananya dari BMT NU dapat berjalan dengan lancar.

2. Penentuan nisbah bagi hasil yang dilakukan oleh KSPPS BMT NU Cabang Wringin Kabupaten Bondowoso dalam pembiayaan mudharabah menggunakan metode perhitungan berdasarkan pendapatan kotor rata-rata. Dari hasil penjumlahan tersebut yang nanti akan disepakati oleh pihak BMT NU dan nasabah/anggota yang akan menjadi acuan perhitungan dalam pembagian hasil.

3. Perlakuan akuntansi untuk pembiayaan mudharabah pada KSPPS BMT NU Cabang Wringin Kabupaten Bondowoso jika dilihat dari PSAK No. 105 masih ada beberapa bagian yang masih belum sesuai yaitu dalam pengakuan dan pengungkapan. Menurut PSAK No. 105 pada paragraf 22 bahwa "pengakuan penghasilan usaha mudharabah dalam praktik dapat diketahui berdasarkan laporan bagi hasil atas realisasi penghasilan usaha dari pengelola dana. Tidak diperkenankan mengakui pendapatan dari proyeksi hasil usaha". Namun BMT NU berdasarkan pendapatan kotor rata-rata. Sedangkan dalam pengungkapan dilihat dari PSAK No. 105 paragraf 38 menyatakan bahwa pemilik dana mengungkapkan rincian jumlah investasi mudharabah berdasarkan jenisnya, tetapi di BMT NU dalam pengungkapanya tidak diperinci berdasarkan jenisnya dan hanya diungkapkan dalam seluruh jumlah investasi mudharabah.

\section{Saran}

Dari penelitian atau pembahasan sebelumnya dan kesimpulan yang telah dijelaskan sebelumnya, maka peneliti memberikan saran sebagai berikut:

1. Untuk KSPPS BMT NU Cabang Wringin Kabupaten Bondowoso harus menerapkan PSAK No. 105 pada pembiayaan mudharabah dengan benar mulai dari pengakuan, pengukuran, penyajian dan pengungkapan pada pembiayaan mudharabah serta disarankan juga untuk menyesuaikan metode penentuan nisbah bagi hasil dengan PSAK No. 105 yang menyatakan bahwa "pembagian hasil usaha mudharabah dapat dilakukan berdasarkan prinsip bagi hasil atau bagi laba. Jika berdasarkan prinsip bagi hasil, maka dasar pembagian hasil usaha adalah laba bruto (gross profit) bukan total pendapatan usaha (omset). Sedangkan jika berdasarkan prinsip bagi hasil laba, dasar pembagian adalah laba neto (net profit) yaitu laba bruto dikurangi beban yang berkaitan dengan pengelolaan dana mudharabah"

2. Untuk peneliti selanjutnya dapat menambahkan variabel bagi hasil yang lainnya dan mungkin dapat diperbandingkan dengan bagi hasil pada pembiayaan mudharabah

\section{Daftar Rujukan}

Antonio, Muhammad Syafi'i. 2001. Bank Syariah Dari Teori Ke Praktik. Jakarta: Gema Insani Press

Debby, dkk. 2015. Faktor-faktor yang Dipertimbangkan dalam Penentuan Nisbah Bagi Hasil Deposito Mudharabah dan perlakuan Akuntansinya pada BPR Syariah. Skripsi. Universitas Jember. 
Harahap, Sofyan Syafri. 2008. Teori Akuntansi. Jakarta: Rajawali Pers. Edisi 10.

IAI. 2017. PSAK Syariah. Jakarta: Ikatan Akuntansi Indonesia.

Mochamad, dkk. 2014. Faktor-Faktor yang Dipertimbangkan dalam Penetapan Nisbah Bagi Hasil Pembiayaan Mudharabah Menggunakan Metode Revenue Sharing pada Baitul Maal Wattamwil

(BMT) (Studi pada BMT Bina Tanjung dan BMT UGT Sidogiri Wirolegi Kabupaten Jember). Artikel Ilmiah. Universitas Jember.

Nawawi, Hadari. 1998. Metodologi Bidang Sosial. Yogyakarta: Gajah Mada University Pers

Oksita, Gayuh. 2011. Faktor-faktor yang Dipertimbangkan Dalam Penentuan Nisbah Bagi Hasil Pembiayaan Mudharabah Pada BMT. Skripsi. Universitas Jember.

Sanusi, Anwar. 2011. Metodologi Penelitian Bisnis. Jakarta: Salemba Empat.

Skob, Hafisman. 2016. Analisis Penerapan Sistem Bagi Hasil pada Pembiayaan Mudharabah pada Koperasi Simpan Pinjam Syariah (KJKS). Skipsi. Universitas Muhammadiyah Yogyakarta.

Sugiyono. 2015.Metode Penelitian Kuantitatif dan Kualitatif, dan R\&D. Bandung: Alfabeta.

Timami dan Soejoto. 2013. Pengaruh dan Manfaat Bagi Hasil Terhadap Jumlah Simpanan Deposito Mudharabah Bank Syariah Mandiri di Indonesia. Jurnal Pendidikan Ekonomi. Vol. 1 No 3. 27 Agustus 2013.

Turrosifa, Kamila. 2013. Penerapan PSAK No. 105 dalam Transaksi Pembiayaan Mudharabah pada Bank Syariah. Jurnal Ilmu dan Riset Akuntansi. Volume 2 Nomor 8. 2013.

Wahyudi, Firman. 2015. Penentuan Nisbah Bagi Hasil pada Pembiayaan Mudharabah dan Musyarakah dan Perlakuan Akuntansinya pada Bank Syariah. Artikel Ilmiah Mahasiswa. 2015.

Yaya Rizal, Martawireja Aji Erlangga dan Abdurrahi Ahim. 2012. Akuntansi Perbankan Syariah: Teori dan Praktik Kontemporer. Jakarta: Salemba Empat. 